\title{
Utilization of Facility Based Health Care and Associated Factors During COVID 19 Pandemic in Oromia Regional State of Ethiopia
}

\author{
Sileshi Garoma Abeya ( $\sim$ garomaabe@gmail.com ) \\ Federal Ministry of health \\ Segni Bobo Barkesa \\ Federal Ministry of health \\ Chala Gari Sadi \\ Federal Ministry of health \\ Seada Ahmed Mohammed \\ Oromia Region Health Bureau \\ Endale Bacha Wako \\ Oromia Region Health Bureau \\ Haji Aman Deybasso \\ Federal Ministry of health \\ Dereje Duguma Gemeda \\ Federal Ministry of health \\ Fekadu Yadeta Muleta \\ Federal Ministry of health \\ Mengistu Bekele Hurisa \\ Oromia Region Health Bureau \\ Dereje Abdena Bayisa \\ Oromia Region Health Bureau \\ Gemechu Shume Bajiga \\ Oromia Region Health Bureau \\ Birhanu Kenate Sori \\ Oromia Region Health Bureau
}

\section{Research Article}

Keywords: Coronavirus, health service, utilization, Oromia, Ethiopia

Posted Date: December 13th, 2021

DOI: https://doi.org/10.21203/rs.3.rs-966887/v1

License: (c) (i) This work is licensed under a Creative Commons Attribution 4.0 International License. Read Full License 


\section{Abstract}

Background: The utilization of facility-based health care services was among the means to tackle the transmission of the COVID 19 and protection of better health. However, reluctance to the utilization of facility-based health care services has been reported to be a major problem everywhere in the globe. This study was to assess the utilization of facility-based health care and associated factors among adults in Oromia regional state, Ethiopia.

Methods: Community-based cross-sectional studies were conducted using a quantitative approach. Data was collected from 2751 adults aged 18 years and above using an interviewer-administered structured questionnaire. The collected data were entered into Epi info version 7.2.0.1 and analyzed using STATA 15. Bivariate and multivariable binary logistic regression analyses were conducted to determine the association between the study variables. Odds Ratio with its $95 \% \mathrm{Cl}$ was calculated and P-Value $<0.05$ was used as a cut-off point to declare the significance.

Results: The overall utilization of facility based essential health care was $25.5 \%(95 \% \mathrm{Cl}: 24.6 \%, 26.4 \%)$. Agro-pastoralist (AOR $0.50,95 \% \mathrm{Cl} ; 0.50$, 1.31), urban residence (AOR $0.66,95 \% \mathrm{Cl} ; 0.48,0.92$ ), Orthodox religion followers ( $\mathrm{AOR} 0.58,95 \% \mathrm{Cl} ; 0.41,0.81$ ), and marital statuses in the widowed/divorced/ Separated category (AOR $0.45,95 \% \mathrm{Cl} ; 0.20,0.99$ ), were significantly associated with utilizations of facility based essential Health Care.

Conclusions: Only 646 (25.5\%) of respondents visited health facilities after the commencement of the COVID 19 pandemic. Activities to increase the utilization of essential health care services are crucial through appropriate information outlets.

\section{Introduction}

Coronavirus disease 2019 (COVID-19) reported in late December 2019 from Wuhan, China is one of the shocking pandemics for humans [1]. The disease was declared as the sixth public health emergency of international concern [2]. As of March 13, 2021, COVID-19 affects globally, with over 119.7 million confirmed cases and 2.6 million reported [3]. In Africa, over 4 million confirmed cases and over 107 thousand death reported. After the first case appeared on March 13/2020 in Ethiopia, the number of cases and death raised to $+172,571$ and +2510 , respectively in its first-year anniversary $[3,4]$.

The COVID-19 pandemic has challenged healthcare systems worldwide. It is of great interest to policymakers and researchers to understand how healthcare utilization, healthcare spending, and perceived health status have evolved during the spread of the COVID 19 pandemic. Previous studies have only documented snapshots and hampering of healthcare utilization and perceived health status in the midst of the pandemic among the general population in the globe [5].

The government of Ethiopia also declared a state of emergency on April 8th, with measures to prevent transmission including travel restrictions, border closure, and suspension of public gatherings, closure of schools and universities, and requirements for social distancing. The effects of these mitigation strategies on the provision of facility-based health care services have remained a problem [6]. There is a significant association between the COVID 19 pandemic and the utilization of facility-based health care services [6].

Moreover, this might be due to, lacks adequate resources to provide facility-based health care services during and simultaneously manage severe cases of COVID 19, unless the spread of the virus is slowed down. The surveillance for another epidemic-prone disease will also be weakened and death surge from outbreaks of other contagious diseases might become imminent [7]. The health care for maternal, newborn, and child health will be compromised, and women will be forced to give birth at home without a skilled birth attendant. Children will not able to receive vaccines on the scheduled dates and vaccine-preventable diseases will be resurfaced. Provisions of quality and adequate health care services for children, mothers, and elders require special interventions and the engagement of higher-level decision-makers [2]. However, this is currently unclear how well people utilize facility-based health care services and their associated factors over time during the COVID 19 pandemic era.

According to the study done in Gonder city Ethiopia, there were nearly half of the study participants (48.96\%) had utilization of facility-based health care services [8]. But, there is a lack of reliable evidence in Oromia regional states on the utilization of health care services during the COVID 19 pandemic. In order to fill the information gap in the scientific literature and in response to the limited evidence in the country in general and Oromia regional state in particular this study was aimed to assess facility-based health care services utilization and associated factors during $2020 / 21$. Therefore, the result will be beneficial to design strategies for the implementation of effective utilization of facility-based health care during the era of the COVID 19 pandemic.

\section{Methods Study Area}

This study was conducted in the Oromia Regional State of ten selected zones and towns. Oromia is one of the largest and most populous regions in Ethiopia with an estimated population of 39,074, 846 [1]. The same source also indicates that Oromia Regional State is divided into 20 zones, 19 towns, and 333 Woredas (districts). The dominant livelihood of the residents of the region is Agrarianism, Agiro-pastoralism, and Pastoralism. The 
region shares boundary with all regions of the country except Tigray. It is bordered by Somali Regional State to the east; the Amhara region, the Afar region, and the Benishangul Gumuz region to the north; South Sudan, Gambela region and SNNP to the west and Kenya to the south [9, 10].

With regard to public health facilities, there are four specialized referral hospitals, 5 university hospitals, 34 general hospitals, 47 primary hospitals, 1410 health centers, and 7090 health posts. In these institutions, data from Oromia Health Bureau show that there are about 24 gynecologists, 82 emergency surgeons (IESOs), 1922 midwives, 346 general practitioners, and 6500 clinical nurses in the region. The study was undertaken from September 2020 to March 2021 [10, 11].

\section{Study design}

The study was a community-based cross-sectional design. It was conducted using a quantitative approach.

\section{Population}

All adults living in the Oromia Regional State during the study period were the Source population, whereas, all adults living in the selected households of the Oromia region during the study period were the Study Population. This included men and women aged 18 years and above. This general population was clustered into agrarian, semi-agrarian, and pastoralists, from which 20 zones and towns.

\section{Inclusion and Exclusion Criteria}

Men and women aged 18 years and above who have been residing in the area for at least six months were included in the study. Those who were critically sick had hearing difficulties, and were unable to communicate during the data collection time were excluded from the study.

\section{Sample Size Determination}

The sample is required to compare the utilization of facility-based health care among urban population in comparison to rural population is calculated using a formula to compare and test the difference between two population proportions in comparative study designs. In using this formula, the following assumptions are considered:

The proportion of utilization of facility-based health care services among the urban population is $50 \%$ in the absence of the previous study. Under the null hypothesis, where the two proportions are not differing from each other, we considered the maximum tolerable level of difference $\left(P_{1}-P_{2}\right)$ between the two population proportions is 0.05 . Accordingly, we took $P_{1}=0.50$ and $P_{2}=0.45$.. And their average (pooled proportion) is obtained by adding the two proportions and dividing by two. We also considered the following assumptions in calculating the sample size;

$\mathrm{n}_{1}=$ an independent sample size in urban population

$\mathrm{n} 2$ = an independent sample size in rural population

$\mathrm{P}_{1}=$ proportion of respondents who had utilization of facility based health care in urban population,

$\mathrm{P}_{2}=$ proportion of respondents who had utilization of facility based health care in rural population,

$\mathrm{P}=$ an average of the proportions of utilization of facility based health care acceptance in two groups

$\mathrm{Z}_{\alpha / 2}=$ the corresponding value of confidence coefficient at alpha level of 0.05 that is 1.96

$\mathrm{Z}_{\beta}=$ the corresponding value of power at beta level of 0.2 that is 0.84

With these assumptions, considering the scenario where the alternate hypothesis is true and the proportions are significantly different and the general formulae are given as follows.

$$
=\frac{\left\{Z_{1-\alpha / 2} \sqrt{2 \bar{P}(1-\bar{P}]}+Z_{1-\beta}{\sqrt{\left[P_{1}\left(1-P_{1}\right)+P_{2}\left(1-P_{2}\right)\right]}}^{2}\right.}{\left(P_{1}-P_{2}\right)^{2}}
$$

By replacing corresponding values for the symbols in the formulae and having a design effect of 2 and adding for the possible non-response rate, we obtained a total of 2851 respondents where 1426 from urban areas and another 1426 respondents from rural areas (Woredas) were selected [10].

\section{Sampling Procedure}

The region was categorized into three clusters, namely, agrarian, semi-pastoralist, and pastoralists. The main reason to use this method was based on the fact that the region is heterogeneous with regard to economic, cultural, geographic, and climatic conditions. From each geographic area zones and towns were randomly selected and three woredas per zones and three sub-cities per town were also randomly selected to have the participants from the households. After identifying, households in the respective woredas and sub-cities participants were randomly selected to include in the 
study. Using this method the residents have equal and independent chances of being enrolled in the study. Based on these clusters, zones, and towns the desired eligible sample was allocated proportionally. Using population to size proportionate methods the required sample size was determined in each study site. Then, using systematic sample by calculating interval (total HH population of the area/sample size) preferably the household heads or the available eligible were selected and included in the study (Table 1) [10].

Table 1

Proportion of Sample size allocated to zones and towns of the study area, Oromia Region, September 2020 to March 2021

\begin{tabular}{|c|c|c|c|c|c|}
\hline \multirow[t]{2}{*}{ Description } & \multicolumn{5}{|c|}{ Urban sample size 1426} \\
\hline & \multicolumn{5}{|c|}{ Rural sample size $=1426$} \\
\hline \multirow[t]{2}{*}{ Zones /Towns } & \multirow[t]{2}{*}{ Zones pop ${ }^{n}$} & Zone pop ${ }^{n}$ & \multirow[t]{2}{*}{ Sample per zone } & \multirow[t]{2}{*}{ Town pop ${ }^{n}$} & \multirow[t]{2}{*}{ Sample per/town } \\
\hline & & Minus Urba & & & \\
\hline Agrarian & & & 703 & & 1125 \\
\hline North Showa/Fiche & 1690403 & 1645269 & 141 & 45134 & 70 \\
\hline East Shoa/Adama & 1615178 & 1229941 & 105 & 385237 & 600 \\
\hline Bale /Robe & 1886779 & 1813919 & 155 & 72860 & 113 \\
\hline Ilu-Ababbora/Metu & 991,257 & 943105 & 81 & 48152 & 75 \\
\hline East Wollega /Nekemte & 1634387 & 1510903 & 129 & 123484 & 192 \\
\hline South West Shoa / Woliso & 1126028 & 1077684 & 92 & 48344 & 75 \\
\hline Pastoralists & & & 703 & & 1125 \\
\hline West Guji/Bule Hora & 1523137 & 1465246 & 125 & 57891 & 90 \\
\hline Borena /Yabello & 566406 & 539682 & 46 & 26724 & 45 \\
\hline Agro pastoralist & & & 172 & & 135 \\
\hline West Harargie / Chiro & 2667000 & 2611725 & 223 & 55275 & 86 \\
\hline East Harargie/ Haromaya & 3882018 & 3831573 & 328 & 50445 & 79 \\
\hline
\end{tabular}

\section{Data Collection}

The quantitative part of the study involves the collection of quantifiable and measurable data on the implementation of COVID 19 preventive measures and utilization of facility-based health care services endorsed by the government and utilization of essential health care in the health facilities. In this regard, the preparation of the questionnaire was based on the conceptual framework of the study and previous similar research work to answer the objectives. The questionnaire was first prepared in English, and then translated to Amharic and Afaan Oromo for data collection and back to English by different people to ensure its consistency. Health professionals having diplomas and above were recruited based on their previous experiences of data collection and interest in data collection. Data were collected by face-to-face interviews from the eligible. One participant was randomly selected from the household if there were two and above respondents to prevent intra-household correlation.

\section{Quality Assurance}

To enhance the quality of the instruments of the data collection, pre-testing of the questionnaire was undertaken prior to data collection. In addition, three days of training were given for data collectors and supervisors concerning the objective, the tools, methodology, and ethical issues. During the data collection period, collected data were checked for completeness and consistency by the supervisors and principal investigators through close follow-ups before entering it into the prepared template.

Each supervisor was given his own household enumerators and data collectors and reoriented them during each day before data collection and supervises them in the field by going with them as well as at the end of the day by cross-checking the registered households and questionnaire for its completeness for all of enumerators and data collectors. Before starting data entry, unique codes were given to each questionnaire. Missing values and outliers were checked using frequency tabulations, residual plotting and managed accordingly. Data was edited and checked manually by hand for checking completeness both during collection and entering into data entry templates. Responses of respondents described on the completed questionnaires were checked for omission, legibility, and consistency reading [10].

\section{Operational Definitions and Measurements}


Level of Knowledge: Respondents were labeled to have "Good knowledge of utilization of facility-based health care" if they score the mean of the group or above on the 17 closed-ended knowledge questions related to health care utilization [1].

Attitude: Respondents were labeled to have "favorable attitudes towards the implementation of the utilization of facility-based health care services" if they score the mean of the group or above on response from Likert scale of five attitude-related questions and otherwise [1].

Utilization of Facility-Based Health Care: This is considered when the respondents and or family have visited a modern health facility for any one of the health problems since the declaration of COVID 19 pandemic in Ethiopia [12].

\section{Data Management and Analysis}

Data were entered into Epi info version 7.2.0.1, data entry template, and exported to STATA 15 software for further cleaning, and running the analysis. Missing values and outliers were checked by frequency tabulations. Since double data entry was difficult due to its time consuming, the randomly selected $5 \%$ of the data set was double entered to check the accuracy and similarities based on the questionnaires identification numbers and it was found that there was no significant difference. Any decision or changes used on the data set was clearly documented for further explanations of unexpected errors that may happen at the end of the day. In addition, check for the item and unit-missing values, outliers for accuracy, causes of outliers were considered and determined. Finally, the collected data was stored in a separate computer and kept confidential.

The collected data were analyzed using STATA 15 software. An odds ratio with a $95 \%$ confidence interval was used to measure the associations between the study variables. Descriptive statistical analysis such as frequency, percentages, proportions with $95 \% \mathrm{Cl}$, the mean and standard deviation was used.

The associations between the utilization of facility-based health care and independent variables were modeled using binary logistic regression analysis. Simple logistic regression analysis was used to assess the existence crude relationship between independent variables and utilization of facility-based health care services. At this level, the candidate independent variables for multiple regression analysis were selected at P-value $<0.25$ significance level. Multiple logistic regressions were applied to estimate the adjusted effects of independent variables on the utilization of facilitybased health care. The odds of having the utilization of facility-based health care were estimated using an odds ratio within $95 \%$ confidence intervals. At this level, the significance of associations was declared at a p-value of 0.05 . The regression model was developed using a forward stepwise approach. The final fitted model was assessed for multicollinearity using Variance Inflation Factor (VIF) and goodness of fit using the Hosmer and Lemeshow test. The model's ability to correctly classify those subjects who experience outcomes of interest and those who do not was assessed using the Receiver Operating Characteristics (ROC) curve [10].

\section{Results}

\section{Socio-demographic Characteristics of the Study Participants}

About 2851 samples were planned of which 2724 were participated in the study making the response rate of $95.5 \%$. The mean ( \pm SD) age of the respondents was $33.30( \pm 11.34)$ years ranged from 18 to 82 years. The majority $(36.8 \%)$ were within the range from 26 to 35 years.

The majority of the respondents 1512 (73.6\%) were from an agrarian, while 203(9.9\%) were agro-pastoralists cluster areas. Of the respondents 1503 (56.7\%) were urban residents and more than half, 1333(51.4\%) were females. Most, 1818 (68.1\%) of the respondents were married during the data collection period. Regarding their religion, most (41\%) were Orthodox Christian followers. The majority, 2170 (79.9\%) of respondents were Oromo by their ethnicity and 847 (31.2\%) were farmers or pastoralists by their occupation, whereas, $393(14.3 \%)$ were students. About a quarter of the respondents $681(25.1 \%)$ attended secondary school education and about one in ten $306(11.3 \%)$ can read and write. The estimated annual income of the respondents ranged from 1000 ETB to 650,000 ETB with the median $( \pm I Q R)$ of $10,000( \pm 649,000)$ ETB (Table 2). 
Table 2

Socio-demographic characteristics of the respondents, Oromia region, Ethiopia, September 2020 to March 2021

\begin{tabular}{|c|c|c|c|}
\hline Variables & Response Category & Number & Percent \\
\hline \multirow[t]{3}{*}{ Cluster of Respondent $(n=2055)$} & Agrarian & 1512 & 73.6 \\
\hline & Agro-Pastoralists & 203 & 9.9 \\
\hline & Pastoralist & 340 & 16.5 \\
\hline \multirow[t]{2}{*}{ Residence of Respondent ( $n=2651$ ) } & Urban/Town & 1503 & 56.70 \\
\hline & Rural/Woreda & 1148 & 43.30 \\
\hline \multirow[t]{2}{*}{ Sex of Respondent $(n=2591)$} & Male & 1258 & 48.6 \\
\hline & Female & 1333 & 51.4 \\
\hline \multirow[t]{5}{*}{ Age } & $18-25$ yrs. & 725 & 28.1 \\
\hline & $26-35$ yrs. & 949 & 36.8 \\
\hline & $36-45$ yrs. & 603 & 23.4 \\
\hline & $46-55$ yrs. & 171 & 6.6 \\
\hline & $\geq 55$ yrs. & 133 & 5.2 \\
\hline \multirow[t]{3}{*}{ Marital Status of Respondent ( $n=2670$ ) } & Single & 706 & 26.4 \\
\hline & Married & 1818 & 68.1 \\
\hline & Widowed/Divorced/separated & 146 & 5.5 \\
\hline \multirow[t]{4}{*}{ Religion of Respondent ( $n=2723$ ) } & Orthodox & 1111 & 41 \\
\hline & Muslim & 982 & 36 \\
\hline & Protestant & 555 & 20 \\
\hline & Others* & 75 & 3 \\
\hline \multirow[t]{4}{*}{ Ethnicity of Respondent ( $n=2717$ ) } & Oromo & 2170 & 79.9 \\
\hline & Amara & 344 & 12.7 \\
\hline & Tigre & 32 & 1.2 \\
\hline & Others** & 171 & 6.3 \\
\hline \multirow[t]{5}{*}{ Occupation of Respondent $(n=2724)$} & Farmer or pastoralist & 847 & 31.2 \\
\hline & Merchant & 632 & 23.3 \\
\hline & Student & 393 & 14.5 \\
\hline & Gov./NGO worker & 408 & 15.0 \\
\hline & Others $* \star \star$ & 433 & 16.0 \\
\hline \multirow[t]{5}{*}{ Level of Education for Respondent $(n=2709)$} & Can't read and write & 498 & 18.4 \\
\hline & Read and write & 306 & 11.3 \\
\hline & Primary & 590 & 21.8 \\
\hline & Secondary & 681 & 25.1 \\
\hline & Colleges and above & 634 & 23.4 \\
\hline \multirow[t]{2}{*}{ Estimated annual Income } & Less or equal to 10,000 ETB & 932 & 50.4 \\
\hline & 10,001 - 25,000 ETВ & 384 & 20.8 \\
\hline
\end{tabular}

NB: Others include * Catholic and Wakefata

** Sidama, Wolayita and Gurage

*** Work in private organization, house maid, and daily laborer 


\begin{tabular}{|llll|}
\hline Variables & Response Category & Number & Percent \\
\hline & $25,001-50,000$ ETB & 297 & 16.1 \\
& $50,001-100,000$ ETB & 185 & 10.0 \\
& $\geq 100,001$ ETB & 52 & 2.8 \\
\hline NB: Others include * Catholic and Wakefata & & \\
\hline$* *$ Sidama, Wolayita and Gurage & & \\
\hline$* * *$ Work in private organization, house maid, and daily laborer & & \\
\hline
\end{tabular}

\section{Utilizations of facility based health care during COVID 19 pandemic}

The majority of the respondents 1581 (59.3\%) have experienced any diseases like TB, Diarrhea, Typhoid, etc. during COVID-19 pandemics of which only $646(25.5 \%)$ visiting health care.

Most of the participants (51.1\%) were due to fear of COVID-19 transmission and $11.1 \%$ were due to Spiritual believers. In these regards, the overall level of utilizing facility-based essential health care was $25.5 \%$ (95\% Cl: $24.6 \%, 26.4 \%$ ) (Table 3).

Table 3

Utilizations of facility based health care during COVID-19 pandemic, Oromia region, Ethiopia, September 2020 to March 2021

\begin{tabular}{|c|c|c|c|}
\hline Variables & Response & Number & Percent \\
\hline \multirow[t]{2}{*}{ Family member have experienced any diseases like TB, Diarrhea, Typhoid etc. during COVID-19 $(n=2665)$} & No & 1084 & 40.7 \\
\hline & Yes & 1581 & 59.3 \\
\hline \multirow[t]{2}{*}{ Family member who have visited health care (2531) } & No & 1885 & 74.5 \\
\hline & Yes & 646 & 25.5 \\
\hline \multicolumn{4}{|l|}{ Reason for not visiting health care $(n=90)$} \\
\hline Fear of COVID-19 & & 46 & 51.1 \\
\hline Lack of access to health service & & 14 & 15.6 \\
\hline Fear of Stigma & & 11 & 12.2 \\
\hline Spiritual believer & & 10 & 11.1 \\
\hline Kept quit or no answer & & 9 & 10.0 \\
\hline
\end{tabular}

\section{Factors associated with utilization of facility based health care}

Geographical Cluster, participant's age, and Occupation, were found significantly associated with utilization of facility-based health care services at a Bi-variable level. All candidate variables selected by simple logistic regression analysis were subjected to multiple logistic regression models to estimate their adjusted effect on the utilization of facility-based health care services. In this model, the independent effect of explanatory variables was estimated by controlling the effects of possible confounders. Accordingly after adjusted for possible confounders' cluster, area of residence, marital status, and religion were found significantly associated with utilization of facility-based health care services at P-value $<0.05$.

In this study, agro-pastoralist cluster (AOR 0.50, 95\% Cl; 0.50, 1.31), urban residence (AOR 0.66, 95\% Cl; 0.48, 0.92), Orthodox religion followers (AOR $0.58,95 \% \mathrm{Cl} ; 0.41,0.81$ ), Marital status of being Widowed/Divorced/ Separated (AOR $0.45,95 \% \mathrm{Cl} ; 0.20,0.99$ ), were less likely to utilize a facility based essential Health Care Services $(P<0.05)$ (Table 4). 
Table 4

Factors associated with Essential Health Service (EHS) Utilization among respondents, Oromia Region, Ethiopia, September 2020 to March 2021

\begin{tabular}{|c|c|c|c|c|c|}
\hline \multirow[t]{2}{*}{ Variables } & \multirow[t]{2}{*}{ Response Category } & \multicolumn{2}{|c|}{ Essential Health Service Utilization } & \multirow[t]{2}{*}{ COR $[95 \% \mathrm{Cl}]$} & \multirow[t]{2}{*}{ AOR $[95 \% \mathrm{Cl}]$} \\
\hline & & Yes & No & & \\
\hline \multirow[t]{3}{*}{ Cluster } & Agrarian & $358(70.5)$ & $1032(75.2)$ & 1:00 (Ref.) & $1: 00$ (Ref.) \\
\hline & Agro-pastoralist & $52(10.2)$ & $127(9.2)$ & $0.41[0.30,0.57]^{\star \star}$ & $0.50[0.50,1.31]^{\star \star}$ \\
\hline & Pastoralist & $98(19.3)$ & $214(15.6)$ & $0.46[0.36,0.58]$ & $0.96[1.51]$ \\
\hline \multirow[t]{2}{*}{ Residence } & Urban & $325(51.6)$ & $1062(58.7)$ & $0.31[0.27,0.35]^{\star *}$ & $0.66[0.48,0.92]^{\star *}$ \\
\hline & Rural & $305(48.4)$ & $748(41.3)$ & 1:00 (Ref.) & 1:00 (Ref.) \\
\hline \multirow[t]{2}{*}{ Sex } & Male & $318(52.9)$ & $831(46.3)$ & $0.29[0.26,0.34]^{\star \star}$ & $1.10[0.81,1.40]$ \\
\hline & Female & $283(47.1)$ & $962(53.7)$ & 1:00 (Ref.) & 1:00 (Ref.) \\
\hline \multirow[t]{4}{*}{ Age category } & $18-25$ yrs. & $143(24.2)$ & $528(29.4)$ & 1:00 (Ref.) & 1:00 (Ref.) \\
\hline & $26-35$ yrs. & $248(42.0)$ & $634(35.3)$ & $0.27[0.23,0.33]^{*}$ & $1.35[0.92,1.98]$ \\
\hline & $36-45$ yrs. & $146(24.7)$ & $401(22.3)$ & $0.39[0.34,0.45]^{\star}$ & $1.14[0.73,1.78]$ \\
\hline & $>46$ yrs. & $54(9.1)$ & $234(13.0)$ & $0.36[0.30,0.44]^{*}$ & $0.95[0.56,1.62]$ \\
\hline \multirow[t]{3}{*}{ Religion } & Protestant & $136(21.2)$ & $380(20.4)$ & 1:00 (Ref.) & 1:00 (Ref.) \\
\hline & Orthodox & $227(35.4)$ & $801(42.9)$ & $0.36[0.29,0.44]^{*}$ & $0.58[0.41,0.81]^{\star \star}$ \\
\hline & Others \# & $278(43.4)$ & $686(36.7)$ & $0.28[0.25,0.33]^{\star}$ & $1.20[0.85,1.67]$ \\
\hline \multirow[t]{3}{*}{ Marital Status } & Single & $144(22.9)$ & $501(27.3)$ & 1:00 (Ref.) & 1:00 (Ref.) \\
\hline & Married & $457(72.7$ & 1230 (67.1) & $0.29[0.24,0.35]$ & $0.90[0.63,1.28]$ \\
\hline & Others \#\# & $28(4.5)$ & $101(5.5)$ & $0.37[0.33,0.41]^{\star \star}$ & $0.45[0.20,0.99]^{\star \star}$ \\
\hline \multirow[t]{5}{*}{ Level of Education } & Can't read and write & $109(17.0)$ & $348(18.6)$ & $0.31[0.25,0.39]^{\star \star}$ & $0.56[0.30,1.03]^{\star *}$ \\
\hline & Read and write & $86(13.4)$ & $188(10.1)$ & $0.46[0.35,0.59]^{\star *}$ & $0.96[0.52,1.77]$ \\
\hline & Primary & $141(22.0)$ & $408(21.8)$ & $0.35[0.28,0.42]^{*}$ & $1.01[0.58,1.76]$ \\
\hline & Secondary & $160(25.0)$ & $460(24.6)$ & $0.35[0.29,0.42]^{*}$ & $0.75[0.45,1.25]$ \\
\hline & Colleges and above & $144(22.5)$ & $464(24.8)$ & 1:00 (Ref.) & 1:00 (Ref.) \\
\hline \multirow[t]{5}{*}{ Occupation } & Farmer or pastoralist & $233(36.3)$ & $555(29.9)$ & $0.42[0.36,0.49]^{*}$ & $0.81[0.50,1.43]$ \\
\hline & Daily laborer & $93(14.5)$ & $311(16.8)$ & $0.30[0.24,0.38]^{\star}$ & $0.67[0.35,1.30]$ \\
\hline & Merchant & $139(21.7)$ & $427(23.0)$ & $0.33[0.27,0.39]^{\star \star}$ & $0.83[0.48,1.45]$ \\
\hline & Student & $72(11.2)$ & $294(15.8)$ & $0.24[0.20,0.32]$ & $0.70[0.35,1.34]$ \\
\hline & Gov./NGO worker & $104(16.2)$ & $269(14.5)$ & 1:00 (Ref.) & 1:00 (Ref.) \\
\hline \multirow[t]{4}{*}{ Estimated Annual Income in ETB } & $<10,000$ ETB & $220(48.6)$ & $647(52.0)$ & $0.34[0.29,0.40]^{*}$ & $1.01[0.69,1.48]$ \\
\hline & $10,001-25,000$ & $114(25.2)$ & $228(18.3)$ & $0.5[0.40,0.63]^{*}$ & $1.47[0.94,2.30]$ \\
\hline & $25,001-50,000$ & $67(14.8)$ & $205(16.5)$ & $0.33[0.25,0.43]^{\star}$ & $0.92[0.56,1.53]$ \\
\hline & $>50,001 \mathrm{ETB}$ & $52(11.5)$ & $165(13.3)$ & 1:00 (Ref.) & 1:00 (Ref.) \\
\hline \multirow[t]{2}{*}{ Level of knowledge } & Poor & $213(33.0)$ & $835(44.3)$ & $0.26[0.22,0.30]^{\star \star}$ & $0.70[0.52,0.91]^{\star \star}$ \\
\hline & Good & $433(67.0)$ & $1049(55.7)$ & 1:00 (Ref.) & 1:00 (Ref.) \\
\hline \multirow[t]{2}{*}{ Attitude } & Unfavorable & $377(58.4)$ & $1320(70.8)$ & $0.27[0.26,0.32] \star \star$ & $0.64[0.50,0.84]^{\star \star}$ \\
\hline & Favorable & $268(41.6)$ & $544(29.2)$ & 1:00 (Ref.) & 1:00 (Ref.) \\
\hline \multicolumn{6}{|c|}{$N B: * P<0.05 ; * * P<0.01 ; * * * P<0.00$} \\
\hline
\end{tabular}




\section{Discussions}

This study used a community-based cross-sectional design using both quantitative and qualitative approaches aimed to assess the utilization of facility-based health care and associated factors in the Oromia region. In doing so, the level of utilization of facility-based health care was computed.

In this study, during the COVID 19 pandemic about a quarter (25.5\%) visited health institutions for seeking essential health care. This is supporting the evidence as novel coronavirus disease (COVID 19) has disrupted healthcare systems around the world and direct health threat to patients and that strained access to healthcare $[13,14]$. The study participants have a huge gap in visiting the health institution as mentioned above due to fear of transmission from health institutions and belief in divine intervention as protection. Moreover, dealing with COVID-19 is likely to create imbalances in health care provision, disruption of routine essential services, and require redeployment of scarce health personnel across health services [15].

The observed significant reduction might be due to various reasons. Given likely challenges to the health system due to the burden of the disease and the government-mandated mitigation strategies, the provision of facility-based health care services was anticipated to be challenged by staff redeployment to provide the intended services, closures of health facilities or services, and supply-chain difficulties limiting provision of care, as well as reductions in outpatient care attendance due to fear, lockdowns and financial difficulties. In recognition of the burden of the pandemic on the health sector, in April 2020, the Ethiopian Federal Ministry of Health (FMoH) developed national guidelines for managing COVID-19. The national guidelines set standards for surveillance, tracing protocols, COVID-19 treatment centers, as well as health center preparedness, community engagement, and maintaining the effectiveness of facility-based essential health care services during the pandemic.

Respondents in the category of the agro-pastoralist cluster were less than half times less likely to utilize facility-based health care during the COVID 19 global pandemic as compared to agrarians. The result was consistent with the study conducted in different parts of Ethiopia, [6, 165-18] which suggests that there is a significant reduction in utilizations of facility-based health care since the COVID-19 pandemics happened in Ethiopia.

The study also showed that the odds of the utilization of facility-based health care lower among participant's urban areas. This finding is congruent with a study conducted in the Netherlands [18] that showed high utilization of facility-based health care during the COVID 19 pandemic. This might be due to the fact that because of having more information about COVID 19 urban residents might be having a panacea compared to their counterparts [19].

Also, Orthodox Christians were less likely to use facility-based health care utilization compared to protestants. This is consistent with the findings of others as most people from Orthodox Christian followers are using spiritual (Tsebel) during the pandemic [6, 16-18].

Being Widowed/Divorced/ separated were less likely to utilize health care during COVID 19 pandemic compared to participants who were never married. This is consistent with the studies done in Ethiopia [6, 16-18]. This might be due to unmarried or single women have autonomy which is positively associated with maternal health service utilization.

The study also showed that the odds of the utilization of facility-based health care services were lower among participants with a poor level of knowledge. As knowledge is the result of awareness based on obtaining appropriate information it is supported by studies conducted elsewhere [12, 20]. This finding is congruent with a study conducted in the Netherlands [21] that showed high information-seeking behavior was associated with the utilization of facility-based health care services. This might be due to the fact that if the population had prior information about the utilization they are more likely to utilize facility-based health care $[4,21]$.

In this study, the attitude of the respondents towards COVID-19 preventive measures and utilization of facility-based health care services failed to be significant in the multivariate analysis. However, in several studies, those respondents having favorable attitudes towards COVID-19 preventive measures and utilization of facility-based health care services were more likely to adhere towards the mitigation measures than their counterparts [4, 21]. The possible explanation might be that the respondents who had a favorable attitude towards COVID-19 preventive measures and utilization of facility-based health care services might trust the science of mitigation measures and comply with the instructions of these guidelines [21].

As to the limitations of the study, due to the cross-sectional nature of the study design, it might be difficult to ascertain the cause-effect relationship between the study variables. Secondly, social desirability bias might be introduced despite their poor actual implementation. Thirdly, the tool used in this study was developed by the research team based on the context and not previously validated and the reliability was checked using Cronbach's alpha.

\section{Conclusions}

The overall level of utilizing facility-based essential health care was very low (25.5\%). Cluster, residence, religion, and marital status, knowledge, and attitudes were factors associated with Utilizations of facility-based essential Health Care.

Based on the findings of the current study is possible to recommend that, activities to increase the utilization of facility-based health care services endorsed by the government should be strengthened. Indeed, there is no single formula for which measures to include or how to improve the provisions and utilization of facility-based health care services to the needy communities. To be effective, public health and social measures require

Page 9/11 
the engagement of all members of society. Policies and interventions should be accompanied by regular dialogue through trusted channels to provide the right information at the right time. At the same time, other possible strategies to reach households could include providing counseling through those volunteer and health extension workers initiating a home-visit program must be strengthened.

\section{Abbreviations}

COVID 19: Coronavirus disease

ETB: Ethiopian Birr

IQR: Inter quartile range

SD: Standard deviation

\section{Declarations}

\section{Ethics approval and consent to participate}

Ethical approval was obtained from the Ethical Review Board (IRB) of Oromia Regional State Health Bureau. Permission letters were secured from Regional and Zonal Health Offices and shared with the selected health care facilities and community administrators. Informed verbal consent and or assent from participants or legally authorized representative in the households (guardians) for those who were unable to read and write were obtained. This procedure was approved by ethics committee of the Regional Health Bureau as the study was not sensitive and experimental in nature.

Moreover, the ethical standard was considered by investigators (dignity, autonomy, informed consent, confidentiality, anonymity, and the ability to adhere to protocol) and the data security was maintained. Voluntary and informed participation, confidentiality, and safety of participants constituted key principles of the interaction. The study was conducted according to the Helsinki declarations on ethical principles for medical research involving human subjects.

Name and other identifiers were excluded from data collection and analysis procedures for the sake of confidentiality. Confidentiality was granted for information collected by keeping a safe place and coding questionnaires. Moreover, it was the right of the participant to refuse to give information and drop out of the study at any time. Anonymity, autonomy, and confidentiality were secured by giving professional advice for both supervisors and data collectors.

\section{Consent for publication}

Not applicable

\section{Availability of data and materials}

The datasets for the study are available from the corresponding author on reasonable request.

\section{Competing interests}

The present authors declare that they have no competing of interests associated with the publication of this paper.

\section{Funding}

No funding was used because the study was conducted as a routine work

\section{Authors' contributions}

Sileshi Garoma Abeya, Chala Gari Sadi, and Sagni Bobo Barkesa generated the concept, wrote proposal, facilitated finance and logistics, participated in data collection, result write-up, revision and approval of the manuscript. Haji Aman Deybasso has participated in design of the work, data collection, write-up, revision and approval of the manuscript. Seada Ahmed Mohammed, Endale Bacha Wako, Dereje Duguma Gemeda, Fekadu Yadeta Muleta, Mengistu Bekele Hurisa, Dereje Abdena Bayisa, Gemechu Shume Bajiga and Birhanu Kenate Sori participated in data collection and facilitation of administrative issues. 


\section{Acknowledgements}

The study team would like to acknowledge Oromia Region Health Bureau for supporting the research. We also, greatly acknowledge the study participants for their cooperation. Staff members ORHB and the data collectors deserve recognition for their facilitation and contribution, lastly, but not the list the study team would like to acknowledge Mr Segni Bobo for sharing his thesis to use some of the issues in the document.

\section{References}

1. World meter, COVID-19 update, Coronavirus Update (Live): 119,723,984 Cases and 2,653,796 Deaths from COVID-19 Virus Pandemic - World meter (worldometers.info) Available at. https://www.who.int/emergencies/diseases/novel-coronavirus-2019?adgroupsurvey= \{adgroupsurvey\}\&gclid=Cj0KCQjw5JSLBhCXARIsAHgO2Sc264KoWyv3Vt_q4LhQ7XP7Z10noRRD_7yJcYgHSU39MqOpaWUF2XUaAs9yEALw_WCB

2. Health Emergency and Disaster Risk Management Framework.Geneva: World Health Organization; 2019.Available at: https://www.who.int/hac/techguidance/preparedness/health-emergency-and-disaster-risk-management-framework-eng.pdf

3. World Health Organization first case of covid-19 confirmed in Ethiopia. Available at: https://www.afro.who.int/news/first-case-covid-19confirmed-ethiopia

4. Yazew BG., Abate HK, and Mekonnen CK. Knowledge, Attitude and Practice Towards COVID-19 in Ethiopia: A Systematic Review; 2020. Patient preference and adherence, 2021. 15: p. 337.

5. Ahn S, Kim S, and Koh K. Changes in Healthcare Utilization, Spending, and Perceived Health during COVID-19: A Longitudinal Study from Singapore. Spending, and Perceived Health during COVID-19, 2020.

6. Temesgen K, Workie A, and Dilnessa T. The impact of COVID-19 infection on maternal and reproductive health care services in governmental health institutions of Dessie town, North-East Ethiopia, 2020 GC. medRxiv, 2020.

7. Europian Union (EU), EU Expert Group on Health Systems Performance Assessment. Assessing the resilience of health systems in Europe: An overview of the theory, current practice and strategies for improvement. Luxembourg, Publications Office of the European Union. 2020.

8. World Health Organization (WHO). Framework for action in building health systems resilience to climate change in South-East Asia Region. Available from: http://apps.searo.who.int/PDS_DOCS/B5370.pdf. 2017.

9. The Federal Democratic Republic of Ethiopia, Central Statistical Agency Statistical Report on Urban Employment Unemployment Survey, 2020.

10. Abeya SG, Barkesa SB, Sadi CG, Gemeda DD, Muleta FY, Tolera AF, et al. (2021) Adherence to COVID-19 preventive measures and associated factors in Oromia regional state of Ethiopia. PLoS ONE 16(10): e0257373. https://doi.org/10.1371/journal.pone.0257373

11. Oromia Region Health Bureau (ORHB), Annual administrative report, 2019/2020.

12. World Health Organization (WHO). Strengthening preparedness for COVID-19 in cities and urban settings: interim guidance for local authorities. 2020, World Health Organization.

13. SangNam Ahn, Seonghoon Kim, Kanghyock Koh. Changes in Healthcare Utilization, Spending, and Perceived Health during COVID-19: A Longitudinal Study from Singapore. Discussion Paper Series. SEPTEMBER 2020.

14. Emanuel EJ, Persad G, Upshur R, Thome B, Parker M, Glickman A, et al. Fair allocation of scarce medical resources in the time of Covid-19. N Engl J Med. 2020;382(21):2049-55.

15. Liu Y, Chen H, Tang K, Guo Y. Clinical manifestations and outcome of SARS-CoV-2 infection during pregnancy. J Infect. 2020 Mar 4. doi: 10.1016/j.jinf.2020.02.028.

16. Assefa KT, Gashu AW, and Mulualem TD. The impact of COVID-19 infection on maternal and reproductive health care services in governmental health institutions of Dessie town, North-East Ethiopia, 2020 GC. medRxiv, 2020.

17. Sidamo NB, Hussen S, Shibiru T Girma M, Shegaze M, Mersha A, Fikadu T, Gebru T, Andarge E, Glagn M, Gebeyehu S, Oumer B, and Temesgen G. Exploring Barriers to Effective Implementation of Public Health Measures for Prevention and Control of COVID-19 Pandemic in Gamo Zone of Southern Ethiopia: Using a Modified Tanahashi Model. Risk Management and Healthcare Policy, 2021. 14: p. $1219-1232$.

18. Temesgen K, Wakgari N, Tefera B, Tafa B, Alemu G, Wandimu F, Gudisa T, Gishile T, Daba G, Abdissa G, Soboka B. Maternal health care services utilization in the amid of COVID-19 pandemic in West Shoa Zone, Central Ethiopia. medRxiv, 2020.

19. Nivette A, Ribeaud D, Murray AL, Steinhoff A, Bechtiger L, Hepp U, et al. Non-compliance with COVID-19-related public health measures among young adults: Insights from a longitudinal cohort study. 2020.

20. World Health Organization (WHO). Statement on the second meeting of the International health regulations (2005) emergency Committee regarding the outbreak of novel coronavirus (2019-nCoV), 2020. Available: https://www.who.int/news/item/30-01-2020-statement-on-thesecond-meeting-of-the-international-health-regulations-(2005)-emergency-committee-regarding-the-outbreak-of-novel-coronavirus-(2019-ncov)

21. Sagane K, Ishihama Y, Sugimoto H. LGI1 and LGI4 bind to ADAM22, ADAM23 and ADAM11. Int J Biol Sci 2008; 4(6):387-396. doi:10.7150/ijbs.4.387. Available from https://www.ijbs.com/v04p0387.htm 